\title{
Optimal windbreak design for wind-erosion in high-speed railway
}

\author{
Y. Xi, J. Mao \& L. Gao \\ The Civil Institute of Beijing Jiaotong University, Beijing, China \\ G. Yang \\ Institute of Mechanics, Chinese Academy of Sciences, China
}

\begin{abstract}
It is also very important to improve resistant capabilities of wind resistance and structural stability of the windbreak while reducing train aerodynamic load. This article proposes a new type of windbreak with double-layer structure forming a cavity chamber with hole for energy dissipation of crosswind. Numerical simulation was used to analysis the wind protection effect of two kinds of windbreak and their own wind-resistance performance. The results showed that the two types of windbreaks can significantly reduce the train aerodynamic load under the action of crosswind, and the force act on the windbreak with cavity chamber structure is small than on another one with single layer structure. The new windbreak has better effect in aerodynamic load shedding for the train, stronger resistant capabilities of wind resistance and safety of structure. This new windbreak with cavity chamber will provides useful references for design of the wind protection system for high speed train.
\end{abstract}

\section{INTRODUCTION}

Crosswind results mainly in the disturbance of the flow field around the train and causes a rise in additional aerodynamic forces and moments. The resulting combination of forces and moments impairs the rollover threshold of the train, thus causing a major threat to operational safety (Baker, 1990; Baker, 1993; Coleman, 1994; Quinn, 2007). In addition to the magnitude of the relative velocity, the magnitudes of the aerodynamic forces and moments depend predominantly on the wind speed of incidence. Windbreaks have been used to shelter high-speed train operation safety from wind damage. They reduce wind speed and alter the characteristics of airflow around them, inducing changes in the surrounding atmospheric (Cleugh, 1998). The interaction between the windbreak and the airflow is complicated by the turbulent characteristics of the wind and by the complex behavior of natural obstacles. Direct effects are due to adsorption of momentum from the wind flow, thus decreasing wind erosivity. They result in reductions of wind speed and turbulence intensity within a certain distance in the lee.

Besides windbreak height and porosity, the actual form of the wind speed curve depends on other important characteristics of the airflow-windbreak system. These are the approach flow characteristics, such as wind speed, wind direction, turbulence intensity, and atmospheric stability, and external windbreak properties, such as windbreak shape, width, and length (Heisler and Dewalle, 1988). Airflow-windbreak interactions have been described and studied in great detail in some numerical simulation models (Wilson, 1985; Wang and Takle, 1995). These models give insights into airflow around porous barriers. In the Wind Erosion Prediction System (WEPS), windbreak effects are incorporated by a reduction factor of friction velocity that takes into account the distance from the barrier, porosity, and width of the barrier porosity, and width of the barrier. 


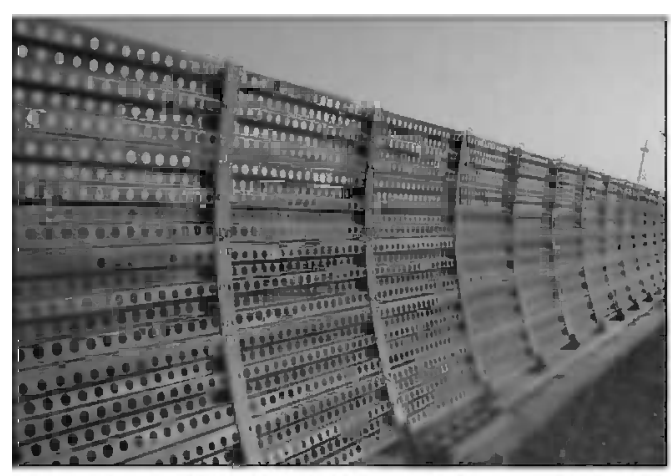

(a) Windbreak in Naniiang line

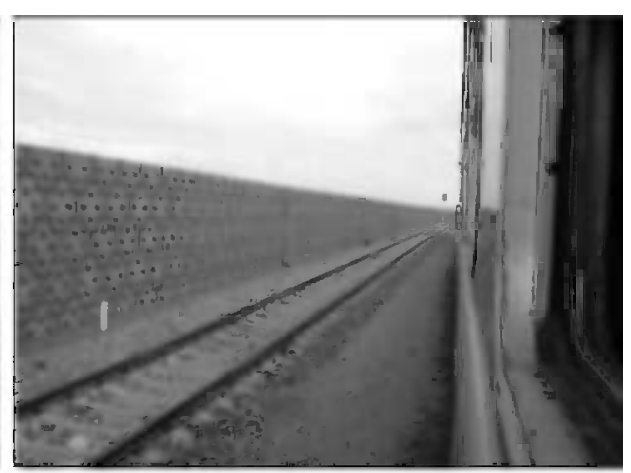

(b) Windbreak in Lanxin line

Figure 1. Windbreak in China.

At present, there are windbreaks mainly in Nanjiang line with arc characteristics and in Lanxin line with flat feature in China, as shown in Figure 1. Considering the comprehensive properties of wind resistance and structure optimization design of the wind shield effect, method and so on, the main objective of this study is to design a windbreak with double corrugated plate and air chamber. And the effect of wind resistance of single windbreak and double will be discussed in the following.

\section{CALCULATION MODEL AND CONDITION}

\subsection{Calculation model}

Numerical simulation of a complete train with a length of about $200 \mathrm{~m}$ requires computational resources beyond those available on existing computers and hence only the flow fields of simplified train configurations can be reliably computed at present. Based on observations made by Cooper (Cooper, 1979), who suggested that the flow structure downstream of a certain distance from the nose (less than one coach length) is more or less constant. Therefore, a decrease in length does not alter the essential physical features of the flow as long as the total length remains above the limit suggested by Cooper. So, as a simplification, the length of the train was limited to that of a train assembly consisting of two identical driving coaches and one trailers (Fig. 2). The total length of the train is $76.125 \mathrm{~m}$ with a length to width to height ratio of 1:0.039:0.051.

Figure 3 shows the dimensions of the flow domain. This domain size was consistent with that used by Schlichiting (Schlichiting, 2000) and was deemed adequate to capture the changes in the flow field during the interaction while giving sufficient distance between the models and the boundaries.

Figure 3 shows a grid system. The finest grid size is near the train surfaces and at the leeward side. The grid size is fine too around the pantograph. The total number of grid, double-layer windbreak with chamber mode and the single-layer mode are 6000 million and 5100 million, respectively.

\subsection{Calculation condition}

Flow around three cases such as no windbreak, single layer windbreak and double layer windbreak with chamber with the high-speed train with $350 \mathrm{~km} / \mathrm{h}$ under the influence of a crosswind have been studied using numerical technique.

In order to prove the wind resistance performance of the double-layer windbreak with chamber, a series of numerical simulations of the flow past the previously described geometry were carried out. The total simulation conditions are listed in Table 1. 


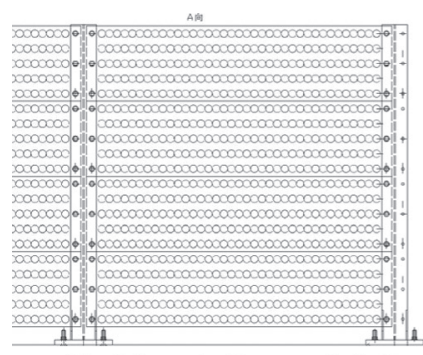

(1) Schematic diagram of windbreak

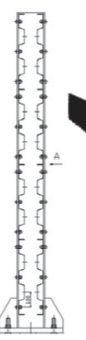

(2) The relative position of the train

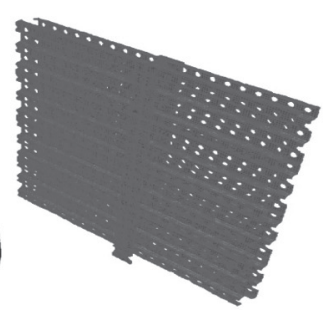

(3) single windbreak

Figure 2. Model.

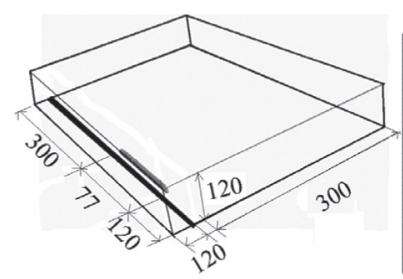

(1) Computational domain

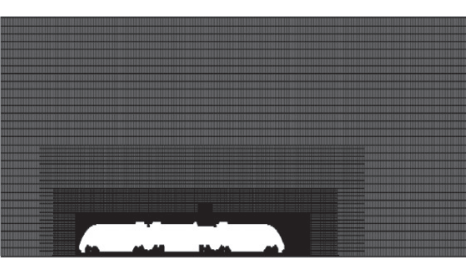

(2) Grid around the train

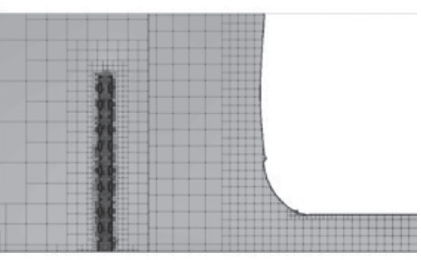

(3) Grid around the windbreak

Figure 3. Computational domain and grid system.

Table 1. Simulation conditions.

\begin{tabular}{llllc}
\hline Scenario & $\begin{array}{l}\text { Train speed/ } \\
(\mathrm{km} / \mathrm{h})\end{array}$ & $\begin{array}{l}\text { Crosswind speed/ } \\
(\mathrm{m} / \mathrm{s})\end{array}$ & $\begin{array}{l}\text { Crosswind } \\
\text { angle }\end{array}$ & $\begin{array}{l}\text { Pore diameter/ } \\
(\mathrm{mm})\end{array}$ \\
\hline No windbreak & 350 & $10,15,20$ & $90^{\circ}$ & 0 \\
Single windbreak & 350 & $10,15,20$ & $90^{\circ}$ & 50 \\
Double windbreak & 350 & 15,20 & $90^{\circ}$ & 50 \\
\hline
\end{tabular}

\section{RESULTS AND DISCUSSION}

\subsection{Pressure distribution around the train}

The flow structure for the wind speed with $20 \mathrm{~m} / \mathrm{s}$ is shown for the case by the two-dimensional vorticity and pressure distribution around the train in Fig. 4. The direction of the crosswind is form lift to right.

From the perspective of vortex motion, the pressure increased in the most surface of the train windward side and the vortex separation generated in the leeward side due to the wind acted directly on the train without energy attenuation in the no windbreak case, as shown in figure 4.

\subsection{Mechanism of the windbreak with chamber}

From the analysis above, part of wind energy is consumed and the direction of the wind deflected because of the windbreak blocking. Thus the pressure of the train is changed and the aerodynamic forces are reduced. The mechanism of the double layer windbreak with chamber is same as the single one. But the load reduction effect of the double layer windbreak with chamber is more obvious. 


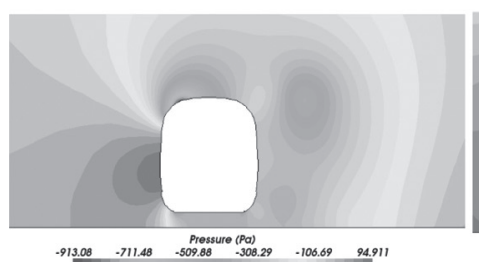

$\begin{array}{rlllll}-913.08 & -711.48 & -509.88 & \text { Pressure } & (\mathrm{PP}) \\ (-308.29 & -106.69 & 94.91\end{array}$

(a) Pressure, no windbreak

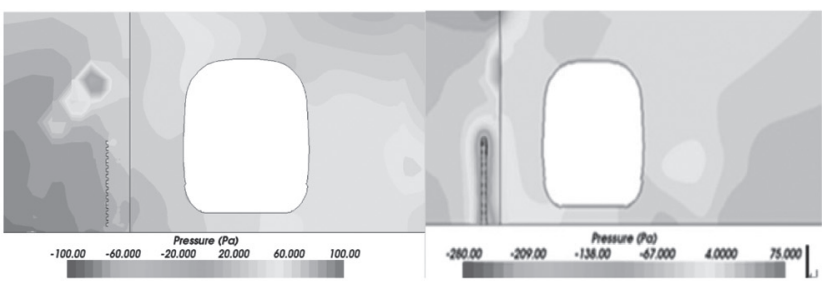

(b) Pressure, single windbreak

(c) Pressure, windbreak with chambers

Figure 4. Vorticity and pressure distribution around the train.

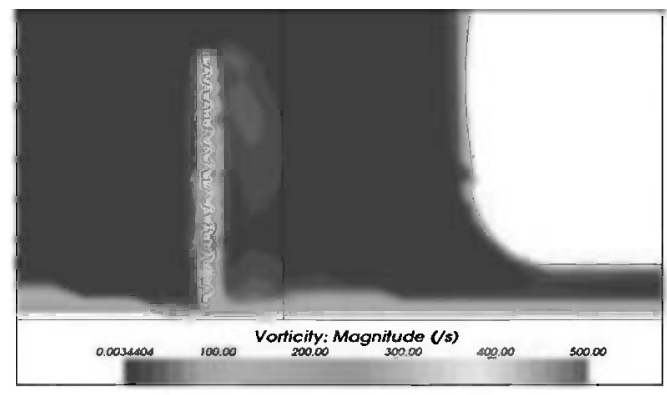

(a l) Vorticity, single windbreak

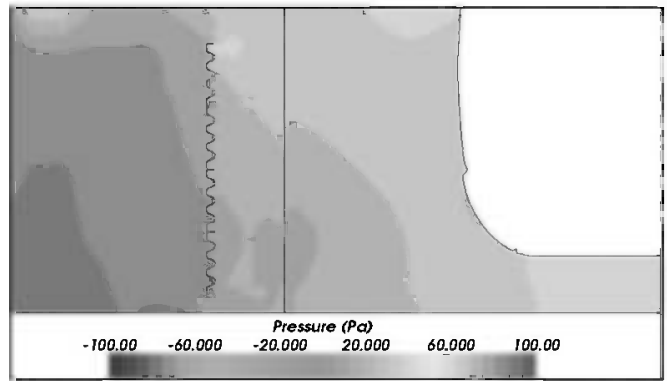

(a2) Pressure, single windbreak

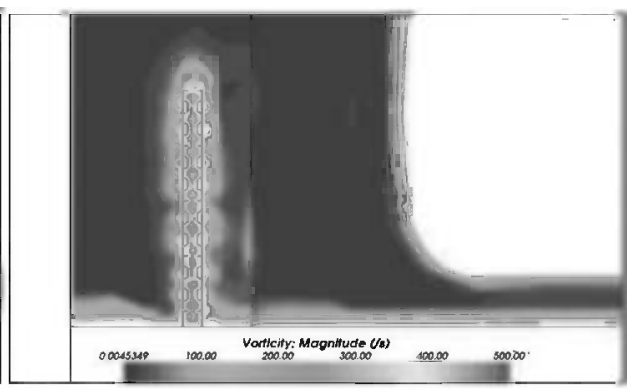

(b1) Vorticity, windbreak with chambers

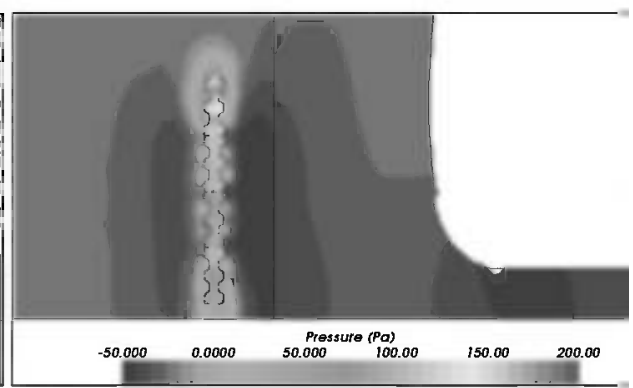

(b2) Pressure, windbreak with chambers

Figure 5. Vorticity and pressure distribution around the windbreak.

The reason is as follows: in the progress of the crosswind flows through the double-layer windbreak, the wind energy loss happened when the air flow through the first layer of the corrugated board. Moreover, the direction of the airflow is changed which flowing out though the second layer of the corrugated board. Furthermore, larger separation eddy and the second energy loss happened. So, the energy dissipation mechanism of the double chamber is much larger than the single windbreak, as shown in Fig. 5.

\subsection{Aerodynamic forcelmoment}

As can be seen from Fig. 4 and Fig. 5, a non-symmetric pressure field is created, resulting in the generation of lateral force and overturning moment. The associated forces and moments act together in the same sense, trying to turn the train over the leeward track.

As shown in Table. 2, the lateral force of the head train and the middle train decreased due to windbreak. But the tail train is complicated which is relation to the wind speed and the type of windbreak. And the effect of the aerodynamic force reduction of double layer windbreak with chamber is better than the single one. Moreover, the aerodynamic moments are all reduced in any crosswind speed with two windbreaks. 
Table 2. Aerodynamic forces/moments (Force/N; Moment/N.m).

\begin{tabular}{|c|c|c|c|c|c|c|c|c|c|}
\hline \multirow[b]{2}{*}{ Force } & \multirow[b]{2}{*}{ Location } & \multicolumn{2}{|c|}{$\begin{array}{c}\text { Crosswind } \\
\text { speed-10 m/s }\end{array}$} & \multicolumn{3}{|c|}{$\begin{array}{l}\text { Crosswind } \\
\text { speed-15 m/s }\end{array}$} & \multicolumn{3}{|c|}{$\begin{array}{c}\text { Crosswind } \\
\text { speed }-20 \mathrm{~m} / \mathrm{s}\end{array}$} \\
\hline & & $\begin{array}{l}\text { No } \\
\text { wind- } \\
\text { break }\end{array}$ & $\begin{array}{l}\text { Single } \\
\text { wind- } \\
\text { break }\end{array}$ & $\begin{array}{l}\text { No } \\
\text { wind- } \\
\text { break }\end{array}$ & $\begin{array}{l}\text { Single } \\
\text { wind- } \\
\text { break }\end{array}$ & $\begin{array}{l}\text { Wind- } \\
\text { break with } \\
\text { chambers }\end{array}$ & $\begin{array}{l}\text { No } \\
\text { wind- } \\
\text { break }\end{array}$ & $\begin{array}{l}\text { Single } \\
\text { wind- } \\
\text { break }\end{array}$ & $\begin{array}{l}\text { Wind- } \\
\text { break with } \\
\text { chambers }\end{array}$ \\
\hline \multirow{3}{*}{$\begin{array}{l}\text { Lateral } \\
\text { force }\end{array}$} & Head & 29370.6 & 2167.09 & 47271.83 & 2720.54 & 844.33 & 66708.2 & 2072.39 & 1676.40 \\
\hline & Middle & 11658.7 & 1453.85 & 19505.65 & 760.47 & 38.19 & 30296.4 & -158.78 & 423.20 \\
\hline & Tail & -1900.3 & 6604.5 & 331.49 & 4794.9 & 3776.75 & 4534.77 & 4596.64 & 810.76 \\
\hline \multirow{3}{*}{$\begin{array}{l}\text { Overturning } \\
\text { moment }\end{array}$} & Head & -9425.2 & 1903.07 & -15109.9 & 1701.21 & 833.48 & -21053 & 863.69 & 351.58 \\
\hline & Middle & 2566.59 & -586.03 & 4015.18 & -440.24 & -362.70 & 3751.64 & -414.21 & 478.22 \\
\hline & Tail & 237.137 & -334.05 & -639.20 & 359.85 & -412.13 & -2728.87 & -777.15 & 120.58 \\
\hline
\end{tabular}

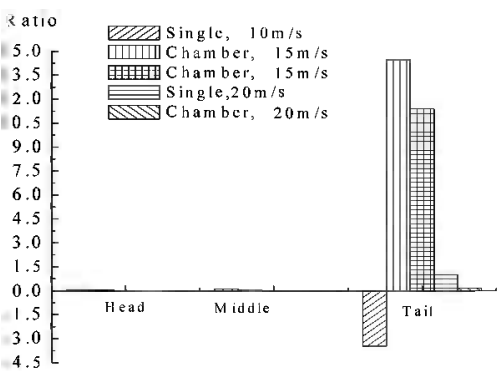

(a) Lateral force

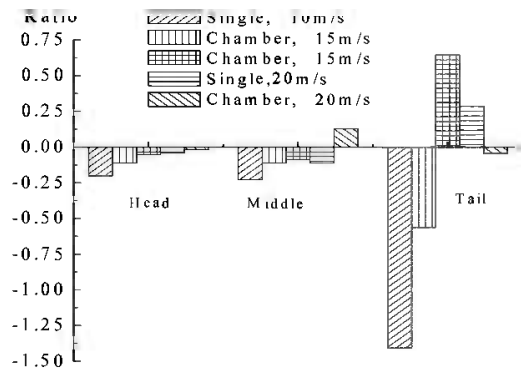

(b) Overturning moment

Figure 6. Comparison of load reducing with two kinds of windbreaks.

Figure 6 is comparison results of load reducing effect with two kinds of windbreaks. The value of the ordinate is the ratio of the windbreak used to no windbreak. From Table 2 and Figure 7, the load reducing effect with windbreaks is very obvious, which changed with the crosswind speed. Compared with single windbreak, double windbreak with chamber can better improve the aerodynamic load.

\section{CONCLUSION}

A certain high-speed train with $350 \mathrm{~km} / \mathrm{h}$ under the influence of crosswind has been studied using numerical technique by solving the steady three-dimensional RANS equations. The body of the train includes most important details including bogies, inter-car gaps, pantograph and rotating wheels on the rail. The dependence of the flow structure and the aerodynamic characteristics on windbreaks have been studied. Based on the analysis of the results, the following can be deduced:

1. A non-symmetric pressure field is created, resulting in the generation of lateral force and overturning moment on the one hand, and an increase of the other components of forces and moments on the other. The associated forces and moments act together in the same sense, trying to turn the train over the leeward track.

2. Two types of windbreaks can significantly reduce the train aerodynamic load under the action of crosswind; and the windbreak with chamber has better effect in aerodynamic load shedding for the train, stronger resistant capabilities of wind resistance.

3. Mechanism of the windbreak with chamber is as follows: in the progress of the crosswind flows through the double-layer windbreak, the wind energy loss happened when the air 
flow through the first layer of the corrugated board. And the direction is changed; and larger separation eddy and the second energy loss happened.

\section{REFERENCES}

Baker, C.J. Assessment of Wind Tunnel Testing Techniques for Ground Vehicles in Cross Winds. Journal of Wind Engineering and Industrial Aerodynamics, 1990, 33(1): 429-438.

Baker, C.J. Behaviour of Road Vehicles in Unsteady Cross Winds. Journal of Wind Engineering and Industrial Aerodynamics, 1993, 49(1): 439-448.

Cleugh, H.A. 1998. Effects of windbreaks on airflow, microclimates and crop yields. Agroforestry Systems 41, 55-84.

Coleman, S.A. Experimental Study of the Aerodynamic Behavior of High Sided Lorries in Cross Winds. Journal of Wind Engineering and Industrial Aerodynamics, 1994, 54(3): 401-429.

Cooper, R.K. The effect of cross-wind on trains. In: Proceedings of Aerodynamics of Transportation, ASME-CSME Conference, 18-20 June, Niagara, 1979, pp. 127-51.

Heisler, G.M. \& Dewalle, D.R. 1988. Effects of windbreak structure on wind flow. Agriculture, Ecosystems and Environment, 22-23, 41-69.

Quinn, A.D. An Investigation of the Wind-induced Rolling Moment on a Commercial Vehicle in the Atmospheric Boundary Layer. Proceedings of the Institution of Mechanical Engineers, Part D: Journal of Automobile Engineering, 2007, 21(11): 1367-1379.

Schlichiting, H. Boundary Layer Theory, Springer. 8th printing, 2000.

Wang, H. \& Takle, E.S. 1995. A numerical simulation of boundary-layer flows near shelterbelts. Boundary-Layer Meteorology 75, 141-173.

Wilson, J.D. 1985. Numerical studies of flow through a windbreak. Journal of Wind Engineering and Industrial Aerodynamics 21, 119-154. 